\title{
PENGARUH PERLAKUAN ALKALISASI DAN VARIASI FRAKSI VOLUME KOMPOSIT POL YESTER SERAT BEMBAN (DONAX CANNIFORMIS) TERHADAP KEKUATAN IMPAK
}

\author{
Akhmad Wahyudi'), Akhmad Syarief ${ }^{2)}$ \\ 1,2Program Studi Teknik Mesin \\ Fakultas Teknik Universitas Lambung Mangkurat \\ JL. Akhmad Yani Km.36 Banjarbaru, Kalimantan Selatan,70714 \\ Telp. 0511-4772646, Fax 0511-4772646 \\ E-mail : akh.wahyudi99@gmail.com
}

\begin{abstract}
The Indonesian state is rich in natural resources, the various benefits of natural resources are useful for human survival. Various kinds of plants in Indonesia are useful as technical material.One of the engineering materials is Composite. Composite is a material formed from a combination of two or more matrials that have stronger mechanical properties than the material forming. The composite consists of two parts: a matrix as a binder or a composite protector and a filler as a composite filler. Natural fiber is an alternative filler, and bemban fiber (Donax Canniformis) is one of the many natural fibers grown in the Hulu Sungai Selatan area of South Kalimantan. From the research result, the influence of volume fraction on composite fiber bemban has the most optimum strength that is on variation $60 \%$ fiber bemban $40 \%$ Polyester with no alkalization that has absorption energy 13.23 joule and the impact price of 0.067 joule $/ \mathrm{mm}^{2}$.
\end{abstract}

Keywords: composite, natural fiber, bemban fiber, impact.

\section{PENDAHULUAN}

Negara Indonesia kaya akan sumber daya alam, berbagai macam manfaat dari sumber daya alam berguna untuk kelangsungan hidup manusia. Salah satu sumber daya alam adalah tumbuh-tumbuhan. Berbagai macam-macam tumbuhan di Indonesia diantaranya bermanfaat sebagai bahan pangan makhluk hidup, sebagai obat-obatan, dan juga bisa bermanfaat sebagai material teknik.

Komposit merupakan salah satu material teknik. Komposit merupakan material yang terbentuk dari paduan dua atau lebih matrial yang memperbaiki sifat mekanik material pembentuknya. Dalam komposit ada dua bagian yaitu matrik berguna menjadi pengikat dan pengisi komposit atau biasa disebut filler. Serat alam menjadi alternative filler komposit dikarenakan mudah didapat, densitas rendah, ramah pada lingkungan, dapat diuraikan secara biologi dan mudah diproses. mudah diproses, densitasnya rendah, ramah lingkungan dan dapat diuraikan secara biologi (kusumastuti, 2009).

Bemban atau bamban (Donax canniformis) adalah tanaman liar yang banyak tumbuh di daerah tanah lembab. Bemban banyak ditemukan di wilayah Asia Tenggara, dan di Indonesia menjadi tempat yang banyak di tumbuhi tanaman ini khususnya di daerah Hulu Sungai Selatan, Kalimantan Selatan

Di daerah Desa Balanti, Kecamatan Kalumpang Kabupaten Hulu Sungai Selatan. Bemban tumbuh dimana-mana dengan membentuk pulau-pulau kecil. Bemban tumbuh liar dan tidak tergunakan dengan baik. Masyarakat hanya menggunakan serat bemban untuk mengikat atap kandang hewan yang terbuat dari daun sagu kering dengan bambu. Serat bemban ini dipercaya masyarakat sekitar 
cukup kuat untuk dijadikan pengikat dan bisa bertahan hingga waktu yang cukup lama.

Dikarenakan masalah diatas peneliti melakukan penetlitian yang memanfaatkan serat bemban sebagai filler material komposit, dengan mengambil judul Pengaruh Perlakuan Alkalisasi Dan Variasi Fraksi Volume Komposit Polyester Serat Bemban (Donax canniformis) Terhadap Kekuatan Impak.

\section{Bemban (Donax Canniformis)}

Bemban tumbuh berumpun dan membentuk semak tinggi sampai dengan 4,5 meter. Batang nya berwarna hijau tua, beruas panjang-panjang dan daun-daun tunggal bertangkai. Bamban biasanya dipakai sebagai bahan anyaman pembuatan bakul, tikar, dan lain-lain kerajinan khas kalimantan selatan juga sebagai pengikat atap kandang hewan.

Bemban memiliki kandungan senyawa alami didalamnya. Kandungan tersebut berupa Flavonoid, Polifenol, dan Saponin. Dari ketiga zat tersebut, tumbuhan bemban ini dipercaya dapat digunakan sebagai obat-obatan untuk menyembuhkan beberapa penyakit seperti bisul, peradangan, luka gigitan hewan juga herbal tetes mata.

Masyarakat juga menggunakan serat bemban untuk mengikat atap kandang hewan, karena serat bemban ini dipercaya masyarakat sangat kuat dijadikan pengikat dan dapat bertahan dalam waktu yang lama.

\section{Komposit}

Material komposit adalah material non logam yang memiliki sifat mekanik lebih baik dari pembentuknya. Dikarenakan kebutuhan material yang mengutamakan sifat mekaniknya dan juga dibutuhkan sifat yang lebih ringan sehingga komposit semakin banyak digunakan.

Secara umum material komposit diklasifikasikan dalam tiga macam yaitu, Metal Matrix Composites (MMC), Polymer Matrix Compsites (PMC) dan Ceramics Matrix Coposites (CMC) (Imra, 2009; Jacob, 1994).

Salah satu bentuk struktur komposit adalah Komposit Serat. Komposit serat terbentuk dari matrik dan serat alam atau fiber. Serat alam yang panjang secara alami memiliki kekuatan yang lebih daripada putus-putus.

a. Continous fiber composite (komposit dengan serat lurus panjang)

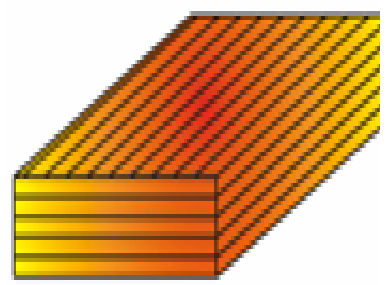

Gambar 1. Serat Lurus 
b. Woven fiber composite (komposit dengan serat dianyam).

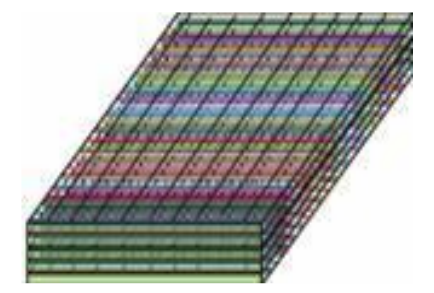

Gambar 2. Serat dianyam

c. Chopped fiber composite (komposit dengan serat pendek atau acak )

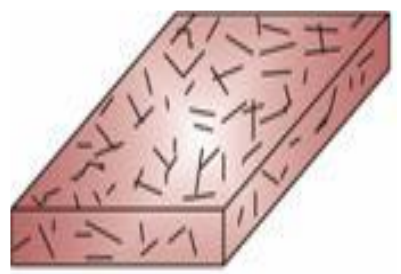

Gambar 3. Serat Acak

d. Hybrid composite (komposit dengan gabungan serat lurus dan serat acak)

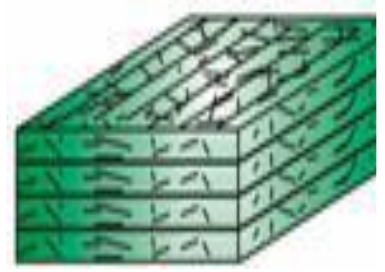

Gambar 4. Serat Lurus dan Acak

\section{Perlakuan Alkali Terhadap Serat Alam}

Komponen utama serat alam adalah selolusa dan lignin juga hemicellulosa memilliki peranan penting terhadap sifat serat.

Dengan perlakuan kimia seperti alkali dapat melarutkan lignin sehingga keduanya berkurang (Vallo, 2004). Namun perlakuan alkali yang terlalu lama dapat mengakibatkan rusaknya serat alam secara permanen sehinggia serat menjadi rapuh.

\section{Uji Impak}

Pengujian impak memiliki tujuan agar mengetahui besar energy serap material sampai material itu patah.. uji impak juga sering disebut uji ketangguhan terhadap beban kejut.

Pengujian ini memiliki 2 teknik pengujian standar yaitu Charpy dan Izod. Pada Penelitian ini pengujian dengan metode charpy.

Harga impak dapat dihitung dengan : 
$H I=\frac{E_{\text {srp }}}{A_{o}}$

di mana:

HI : Harga impak (Joule/mm²)

Esrp : Energi serap (J)

Ao : Luas penampang $\left(\mathrm{mm}^{2}\right)$

\section{METODE PENELITIAN}

Bahan yang digunakan yaitu serat bemban, polyster, katalis, $\mathrm{NaOH}$, aquadest, wax. Dalam penelitian ini menggunakan peralatan yaitu cetakan kaca, timbangan digital, handscoon, penggaris, oven, gelas ukur, gelas plastic, gunting, pisau potong, kikir segitiga, amplas dan mesin uji impak XJ-300.

\section{Prosedur Penelitian}

Prosedur dalam penelitian komposit serat bemban yaitu sebagai berikut :

1. Pada awal penelitian dilakukan:

a. Batang bemban yang sudah didapat dari alam dibersihkan, dipotong, kemudian di iris setebal $1 \mathrm{~mm}$ dan panjang $120 \mathrm{~mm}$.

b. Kemudian serat yang sudah di iris direbus selama \pm 20 menit.

c. Kemudian menentukan serat bemban dengan fraksi volume $40 \%$ serat, $50 \%$ serat, $60 \%$ serat bemban dan di ikat untuk mempermudah proses selanjutnya.

d. Menyiapkan larutan $\mathrm{NaOH}$ masing-masing variasi $2 \%, 4 \%$, dan $6 \%$.

e. Serat bemban yang sudah disiapkan kemudian dimasukkan kedalam larutan $\mathrm{NaOH}$ (untuk serat bemban yang diberi perlakuan alkalisasi) selama \pm 1 jam untuk dilakukan proses alkalisasi.

f. Kemudian serat bemban dikeringkan dengan oven pengering dengan suhu $120^{\circ} \mathrm{C}$ selama \pm 1 jam.

2. Pembuatan Komposit

a. Pertama adalah menyiapkan cetakan spesimen dari kaca dengan ukuran sesuai dengan ASTM D256-00.

b. Menyiapkan resin.

c. Menyiapkan katalis.

d. Menyiapkan serat yang telah dikeringkan.

e. Mengoleskan wax pada cetakan yang telah disiapkan.

f. Mencampur resin dan katalis (katalis sebanyak 1\% dari masa resin).

g. Memulai proses pencetakan komposit dengan memasukkan serat bemban yang telah dikeringkan dan campuran antara resin dan katalis kedalam cetakan.

h. Setelah \pm 24 jam angkat spesimen dari cetakan dan keringkan pada suhu ruangan.

i. Untuk pengeringan spesimen dilakukan dalam ruangan selama \pm 48 jam. 
3. Pengujian Specimen Uji Impak

a. Pembuatan Spesimen Uji impak

Komposit serat bemban dengan dimensi yang akan digunakan pada uji Astm D256-00.

b. Melakukan Pengujian Impak

Sebelum melakukan pengujian pada komposit dilakukan kalibrasi terlebih dahulu agar hasil yang didapat lebih tepat. Kemudian lakukan pengujian impak pada komposit.

\section{Variabel Penelitian}

Penelitian ini menggunakan metode ekperimental. Dibawah ini variable yang digunakan dalam penelitian ini.

1. Variabel bebas yang digunakan adalah perbandingan variasi fraksi volume serat bemban dan resin polyester, yaitu:
a. $\quad 40 \%$ serat bemban : $60 \%$ matrik resin polyester
b. $50 \%$ serat bemban : $50 \%$ matrik resin polyester
c. $60 \%$ serat bemban : $40 \%$ matrik resin polyester

2. Variabel bebas yang digunakan adalah variasi perlakuan alkali, yaitu :
a. Penggunaan alkalisasi $0 \%$
b. Penggunaan alkallisasi $2 \%$
c. Penggunaan alkalisasi $4 \%$
d. Penggunaan alkalisasi $6 \%$

3. Variabel terikat yang digunakan adalah uji impak.

4. Variabel terkontrol yang digunakan :

a. Campuran katalis $1 \%$ dari jumlah massa resin polyester.

b. Cetakan terbuka, metode hand lay-up 
Diagram alir penelitian ini dapat di lihat dalam Gambar 5.

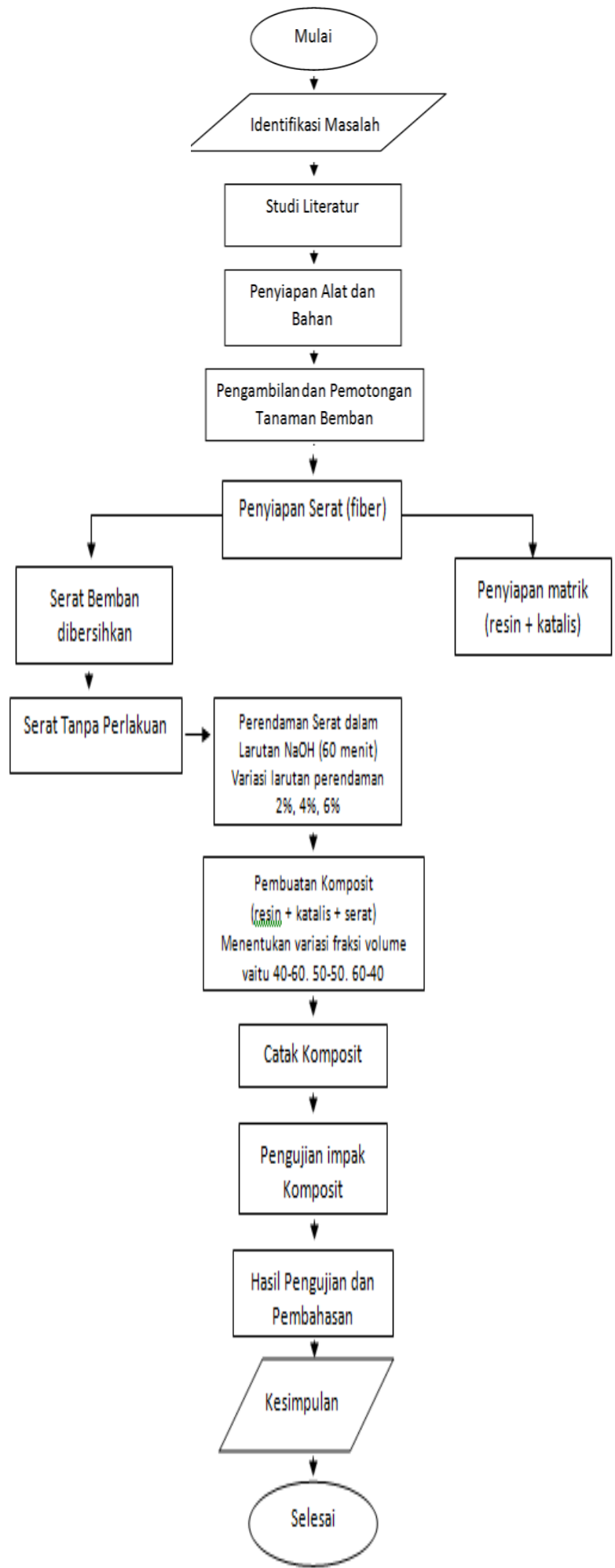

Gambar 5. Diagram Alir Penelitian 


\section{PEMBAHASAN}

Hasil yang diperoleh dari penelitian tentang komposit dengan variasi perbandingan fraksi volume $0 \%, 40 \%, 50 \%, 60 \%$ serat bemban dan dengan perlakuan $\mathrm{NaOH} 0 \%, 2 \%, 4 \%$, dan 6\% terhadap kekuatan seperti pada Gambar 6.

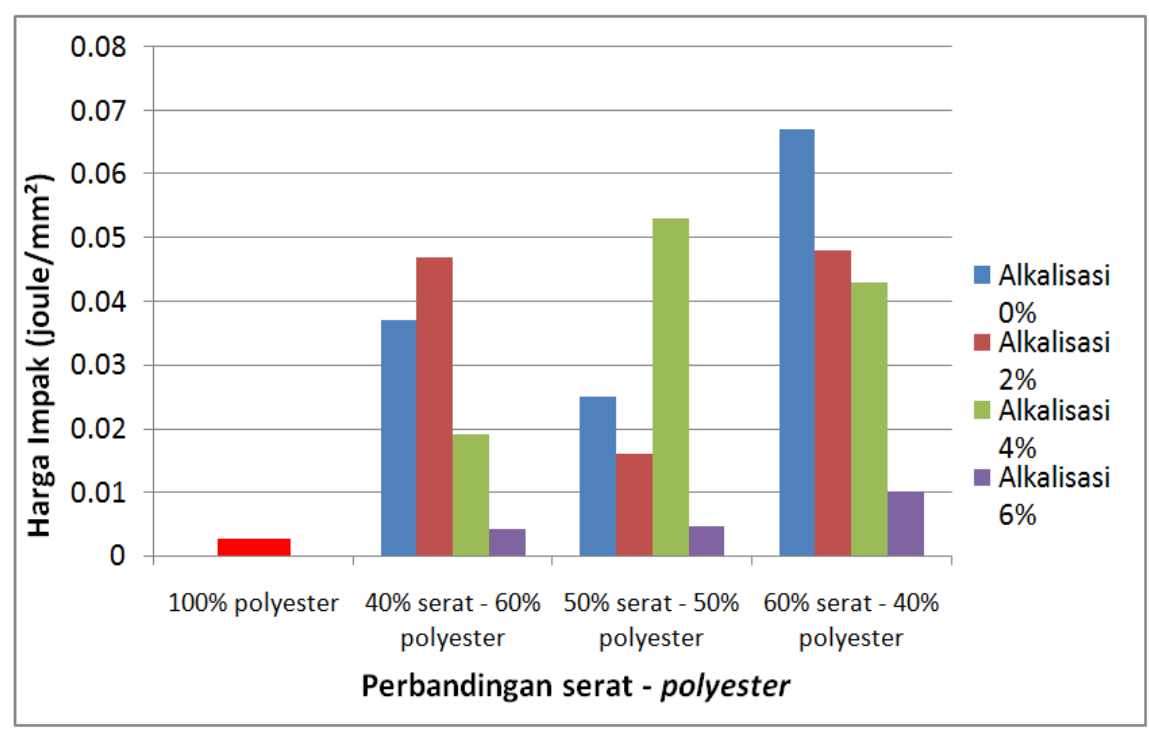

Gambar 6. Grafik Harga Impak Komposit Serat Bemban pada semua variasi

Gambar 6 menunjukkan, perbandingan kekuatan 100\% Polyester dengan komposit serat bemban menunjukkan peningkatan yang besar antara hasil kekuatan pada semua variasi.

Pada komposit yang pertama dengan faksi volume serat bemban $40 \%$ tanpa alkalisasi memiliki kekuatan impak sebesar 0.037 joule $/ \mathrm{mm}^{2}$. komposit yang kedua dengan faksi volume serat bemban $50 \%$ tanpa alkalisasi memiliki kekuatan impak yang menurun yaitu sebesar $0.025 \mathrm{joule} / \mathrm{mm}^{2}$. Dan Pada komposit yang ketiga dengan faksi volume serat bemban $60 \%$ memiliki kekuatan impak yang sebesar 0.067 joule $/ \mathrm{mm}^{2}$.

Selanjutnya adalah komposit dengan variasi alkalisasi menggunakan $\mathrm{NaOH}$ sebesar $2 \%$. Pada komposit yang pertama dengan faksi volume serat bemban $40 \%$ memiliki kekuatan impak sebesar 0.047 joule $/ \mathrm{mm}^{2}$. Pada fraksi volume serat bemban sebesar $50 \%$ dengan harga impak 0.016 joule $/ \mathrm{mm}^{2}$. Komposit dengan fraksi volume serat bemban $60 \%$ memiliki kekuatan impak sebesar 0.48 joule $/ \mathrm{mm}$.

Komposit dengan variasi alkalisasi menggunakan $\mathrm{NaOH}$ sebesar $4 \%$. Pada komposit yang pertama dengan faksi volume serat bemban $40 \%$ memiliki kekuatan impak sebesar 0.019 joule $/ \mathrm{mm}^{2}$. Fraksi volume serat bemban $50 \%$ memiliki harga impak sebesar 0.053 joule $/ \mathrm{mm}^{2}$. Dan pada fraksi volume serat bemban $60 \%$ memiliki kekuatan impak sebesar 0.043 joule $/ \mathrm{mm}^{2}$.

Untuk variasi alkalisasi selanjutnya yaitu menggunakan $\mathrm{NaOH}$ sebesar $6 \%$. Pada komposit yang pertama dengan faksi volume serat bemban $40 \%$ memiliki kekuatan impak sebesar 0.0042 joule $/ \mathrm{mm}^{2}$. Selanjutnya kekuatan impak pada fraksi volume serat bemban sebesar 50\% memiliki harga impak 0.0046 joule $/ \mathrm{mm}^{2}$. Dan pada komposit ketiga dengan fraksi volume serat bemban $60 \%$ kekuatan impak sebesar 0.010 joule $/ \mathrm{mm}^{2}$. 
Rata-rata menunjukkan kekuatan terbaik yaitu pada variasi fraksi volume $60 \%$ serat bemban - 40\% Polyester. Berikut adalah Grafik Perbandingan pengaruh alkalisasi terhadap komposit serat bemban dengan fraksi volume $60 \%$ serat bemban - $40 \%$ Polyester.

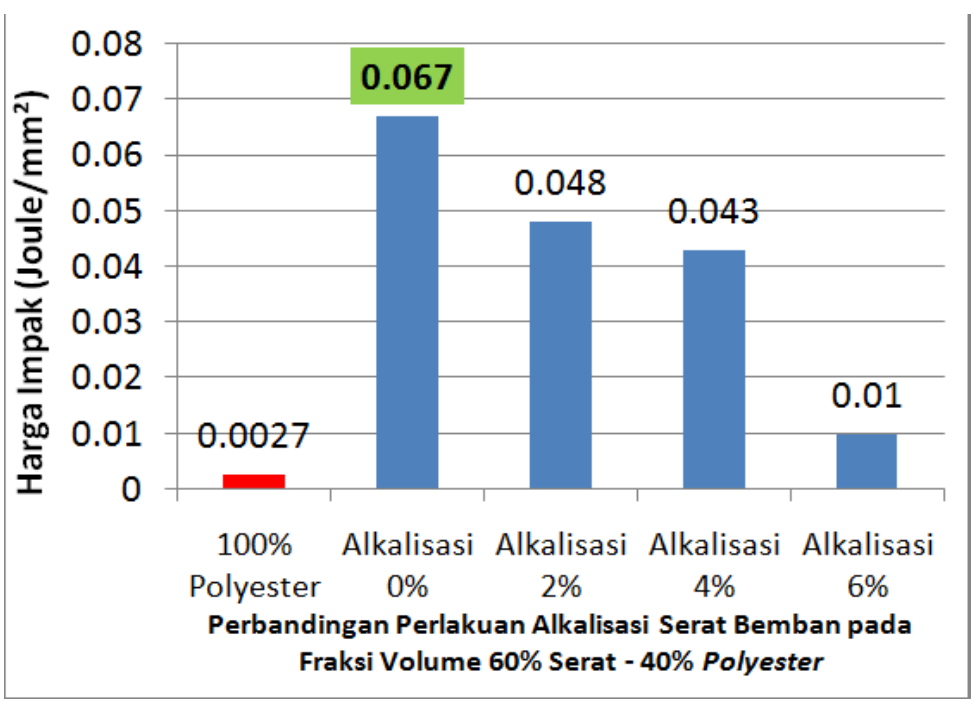

Gambar 7. Grafik Harga Impak Komposit Serat Bemban Fraksi Volume 60\% Serat Terhadap Semua Variasi Alkalisasi

Pada Gambar 7 ketika serat bemban diberi perlakuan, kekuatan komposit serat bemban terhadap kekuatan impak mengalami penurunan seperti pada Semakin tinggi persentase larutan $\mathrm{NaOH}$ nya semakin berkurang kekuatan komposit serat bemban terhadap kekutan impak. Dapat disimpulkan bahwa serat bemban dengan perlakuan alkalisasi menggunakan larutan $\mathrm{NaOH}$ menurunkan kekuatan impak komposit serat bemban.

Berikut adalah foto spesimen setelah pengujian impak yaitu spesimen $100 \%$ Polysester, dan komposit serat bemban yang memiliki kekuatan paling optimal yaitu pada variasi $60 \%$ serat - $40 \%$ polyester dengan serat bemban tanpa alkalisasi ( $\mathrm{NaOH} \mathrm{0 \% ).}$

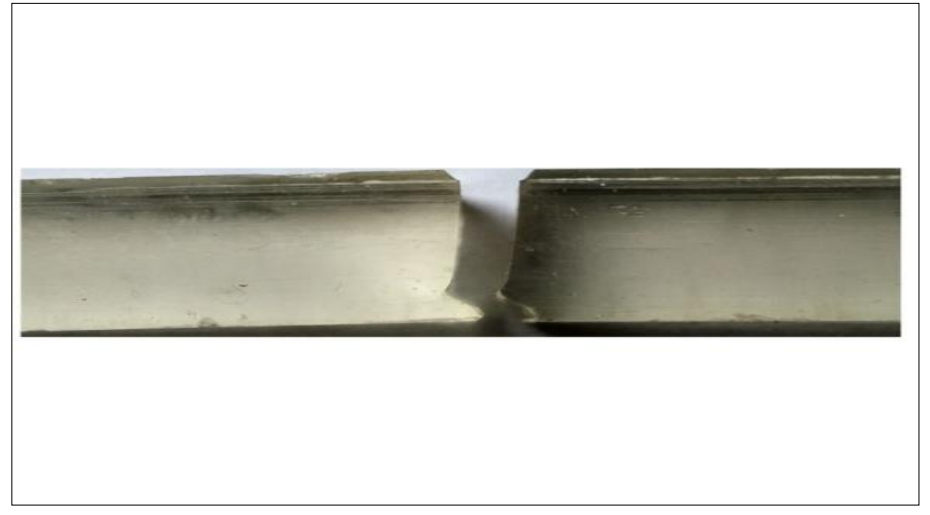

Gambar 8. Spesimen 100\% Polyester 


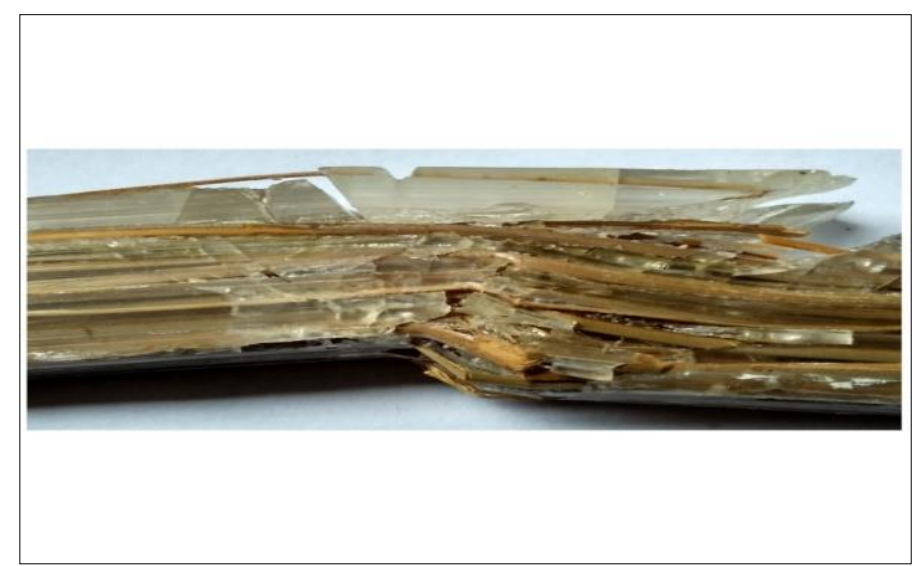

Gambar 9 . Spesimen $60 \%$ serat bemban $40 \%$ Polyester

Pada spesimen $100 \%$ polyester memiliki kekuatan paling rendah yaitu dengan harga impaknya 0.0027 joule $/ \mathrm{mm}^{2}$, dan pada spesimen $60 \%$ serat $-40 \%$ polyester memiliki kekuatan paling optimal dengan harga impak 0.067 joule $/ \mathrm{mm}^{2}$. Ini menunjukkan bahwa dengan diberi filler serat bemban memperbaiki sifak mekanik material pembentuknya. Dilihat dari bentuk patahannya $100 \%$ polyester terjadi patahan getas, sedangkan pada komposit serat bemban pada variasi $60 \%$ serat $40 \%$ polyester terjadi pergesaran retakan dan belum terjadi patahan, ini disebabkan kuatnya ikatan matrik dengan filler.

\section{KESIMPULAN}

Seperti pada hasil pneltian yang sudah dibahas sebelumnya didapat kesimpulan yaitu :

1. Pengaruh perlakukan alkalisasi serat bemban menggunakan larutan $\mathrm{NaOH}$ $0 \%, 2 \%, 4 \%$ dan $6 \%$ terhadap harga impak komposit serat bemban yang didapat yaitu semakin tinggi variasi persentase alkalisasinya maka semakin menurun harga impaknya. Dan pada komposit serat bemban yang tanpa diberi perlakuan alkalisasi ( $\mathrm{NaOH} 0 \%$ ) memiliki kekuatan tertinggi dengan variasi $60 \%$ serat $40 \%$ polyester yang harga impaknya 0.067 joule $/ \mathrm{mm}^{2}$.

2. Pengaruh Fraksi Volume pada komposit berpenguat serat bemban yang memiliki kekuatan paling optimal yaitu pada variasi $60 \%$ serat bemban $40 \%$ Polyester yaitu memiliki energi serap 13.23 joule dan harga impak sebesar 0.067 joule $/ \mathrm{mm}^{2}$. 


\section{DAFTAR PUSTAKA}

Jacobs J.A.,Kilduft T.K. (1994). Engineering Material Technology Structure, Processing, Property andSelection 2. Prentice Hall,Inc A Simon Schuster Company, USA.

Oza, S (2010) Thermal and Mechanical Properties of recycled High Density Polyethylene/hemp fiber Composites, University City Blvd Charlotte, NC, 28223, USA, pp. 31-36.

Syarief, A. (2011) Pengaruh Perlakuan Potassium Permanganate (KMnO4) Terhadap Kekuatan Lentur dan Impak Komposit berpenguat Anyaman Serat Purun Tikus (Eleocharis Dulcis) Bermatrik Polyester, Penelitian, Universitas Brawijaya.

Vallo Caludia, Jose M. Kenny Analia Vazquez and viviana P. Cyras (2004) Reinforced with Sisal Fibre Efect of Chemical Treatment on the mechanical Properties of starch-based blends. Journal of Composite Material 2004;38;1387, DOI:10.1177/ 0021998304042738. 